\title{
Enantioselective Organocatalytic Four-Atom Ring Expansion of Cyclobutanones: Synthesis of Benzazocinones
}

\author{
Yirong Zhou, Yun-Long Wei, Jean Rodriguez,* and Yoann Coquerel*
}

\begin{abstract}
An enantioselective Michael addition- four-atom ring expansion cascade reaction involving cyclobutanones activated by a $\mathrm{N}$-aryl secondary amide group and ortho-amino nitrostyrenes has been developed for the preparation of functionalized eight-membered benzolactams using bifunctional aminocatalysts. Taking advantage of the secondary amide activating group, the eight-membered cyclic products could be further rearranged into their six-membered isomers having a glutarimide core under base catalysis conditions without erosion of optical purity, featuring an overall ring expansion- ring contraction strategy.
\end{abstract}

B fused to a benzene ring, are privileged scaffolds that can be found in various synthetic and natural products endowed with important biological activities (Figure 1). ${ }^{[1,2]}$ However, the

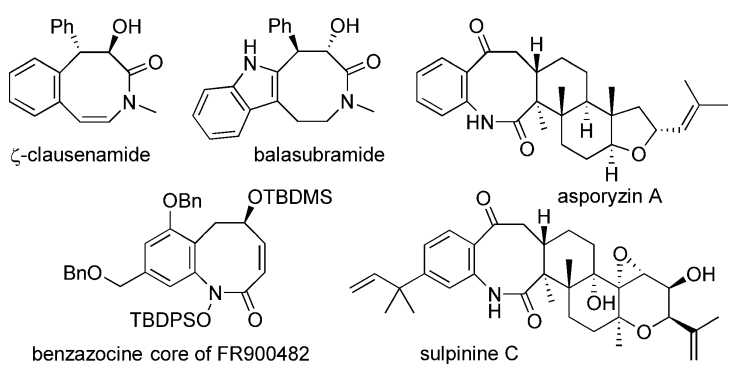

Figure 1. Selected examples of benzazocinones in natural products and bioactive molecules.

construction of medium-sized rings by organic synthesis is notoriously difficult because of inherent unfavorable enthalpic and entropic factors, as well as undesired trans-

[*] Dr. Y. Zhou, Y.-L. Wei, Prof. Dr. J. Rodriguez, Dr. Y. Coquerel Aix Marseille Université, CNRS, Centrale Marseille, ISM2

13397 Marseille (France)

E-mail: jean.rodriguez@univ-amu.fr

yoann.coquerel@univ-amu.fr

Dr. Y. Zhou

Key Laboratory of Functional Small Organic Molecules Ministry of Education, Jiangxi Normal University 330022, Nanchang (China)

근 Supporting information including experimental procedures, full

iD characterization data, details of the computational studies, and single crystal $\mathbf{X}$-ray diffraction analysis data for $\mathbf{3} \mathbf{b}$ and the ORCID identification number(s) for the author(s) of this article can be found under:

https://doi.org/10.1002/anie.201810184. annular interactions. ${ }^{[1]}$ Although steady progresses have been made for the synthesis of medium-sized heterocycles, the direct synthesis of azocane derivatives remains a largely unsolved issue, ${ }^{[3]}$ especially when considering catalytic enantioselective approaches. There has been only a handful of examples of enantioselective syntheses reported on this poorly-charted area of chemical space (Scheme 1a). The Rovis group described a rhodium(I)-catalyzed [4+2+2] cycloaddition using a chiral phosphoramidite ligand, ${ }^{[4]}$ while Dong and co-workers developed a rhodium(I)-catalyzed redox neutral annulative hydroacylation employing a chiral diphosphine ligand. ${ }^{[5]}$ Lately, two organocatalytic approaches were reported relying on Lewis base catalysis: Lu, Ullah, and co-workers proposed a (4+4) annulation based on allenes activation with a chiral phosphine catalyst to afford azocines, ${ }^{[6]}$ and the group of Romo used the reactivity of catalytically generated $\alpha, \beta$-unsaturated acyl ammonium salts with a chiral tertiary amine catalyst in $(5+3)$ annulations. $^{[7]}$ Over the last two decades, organocatalytic cascade reactions have established as a general and sustainable strategy to rapidly access highly functionalized, structurally diverse and complex molecules free from metal residues. ${ }^{[8]}$ Nevertheless, most of the established organocascades focus on the preparation of energetically favorable five- and six-membered rings. Otherwise, ring expansion strategies provide an appealing way to prepare medium-sized rings from readily available small rings. ${ }^{[9]}$ Herein, we propose a direct enantioselective organocatalytic synthesis of benzazocinones based on a Michael addition- four-atom ring expansion cascade from activated cyclobutanones and ortho-amino nitrostyrene derivatives using bifunctional aminocatalysts (Scheme $1 \mathrm{~b}$ ). The base-catalyzed ring contraction of benzazocinone products into their six-membered ring isomers having a glutarimide core with retention of optical purity is also demonstrated.

Based on our previous work, ${ }^{[10]}$ the cyclobutanone 1a activated by a $N$-aryl secondary amide group at the $\alpha$ position and the ortho-amino nitrostyrene derivative $\mathbf{2}$ a were selected as the prototypical substrates to test our hypothesis with the bifunctional aminocatalyst $\mathbf{O C 1}^{[11]}$ in toluene, meta-xylene, or dichloroethane. To our delight, the expected benzazocinone product $\mathbf{3 a}(\mathrm{dr}=4: 1$ to $5: 1)$ was identified as the largely major product with $70 \%$ yield in toluene and meta-xylene and $51 \%$ yield in dichloroethane, with excellent enantioselectivities (Scheme 2). No Michael adduct or hemiketal intermediate was detected in the crude reaction mixtures. With the intention to optimize these results, organocatalysts OC2 OC12 were screened for the same reaction. ${ }^{[12]}$ The results are listed in Scheme 2. It was found that cinchonine and quinidine-derived squaramides $\mathbf{O C 1}$ and $\mathbf{O C 2}$ are optimum for the synthesis of benzazocinone $\mathbf{3} \mathbf{a}$ in terms of practic- 
a) previous work from acyclic precursors

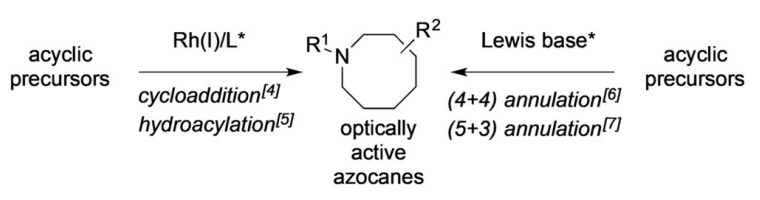

b) this work: Michael addition / four-atom ring expansion organocascade

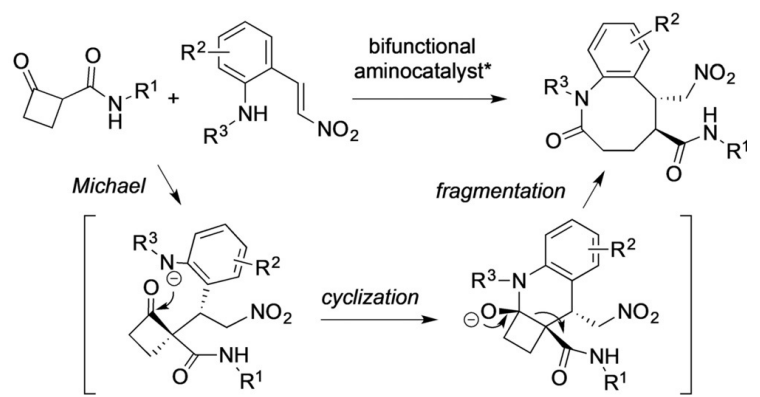

Scheme 1. Enantioselective approaches to azocane derivatives.

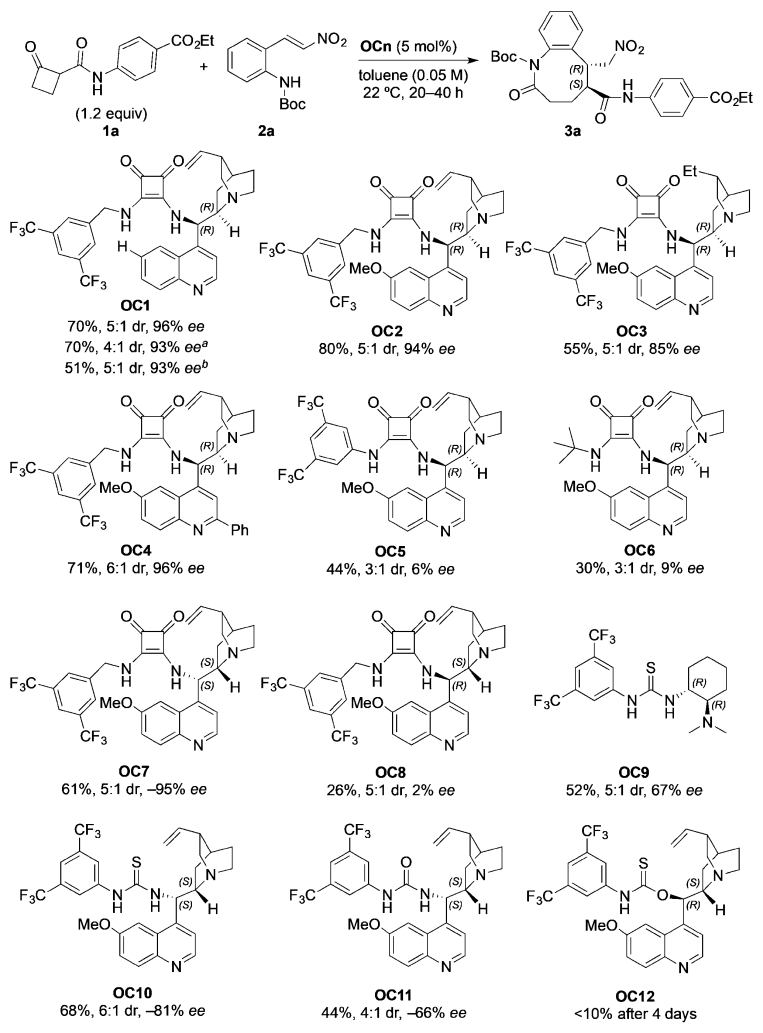

Scheme 2. Organocatalysts screening. Yields for isolated pure products. The dr values were determined by ${ }^{\top} \mathrm{H}$ NMR analysis of the crude reaction mixtures, and $e e$ were determined for the pure products by HPLC analyses on chiral stationary phases. [a] Reaction performed in meta-xylene. [b] Reaction performed in 1,2-dichloroethane. ability, yield, and enantioselectivity. Catalyst $\mathbf{O C} 3$, a hydrogenated version of catalyst $\mathbf{O C} 2$, afforded the product in significantly reduced efficiency and enantioselectivity, while catalyst $\mathbf{O C 4}$, a sterically hindered version of catalyst $\mathbf{O C 2}$, gave a comparable result to catalyst $\mathbf{O C 1}$. Catalysts $\mathbf{O C 5}$ and OC6 having a $N$-3,5-bis(trifluoromethyl)phenyl and a $N$-tertbutyl, respectively, in place of the $N$-3,5-bis(trifluoromethyl)benzyl group found in $\mathbf{O C 2}$ gave only modest yields of $\mathbf{3 a}$ with complete loss of the enantioselectivity. Catalyst OC7 derived from quinine is the pseudo-enantiomer of catalyst $\mathbf{O C 2}$, and as such it delivered $\mathbf{3} \mathbf{a}$ in similar yield but opposite and still excellent enantioselectivity. With catalyst $\mathbf{O C 8}$, a diastereomer of $\mathbf{O C 2}$, the reaction afforded only $26 \%$ yield of $\mathbf{3 a}$ as a nearly racemic product, indicating a strong mismatch effect in this case. The replacement of the squaramide double hydrogen bond donor moiety by a thiourea in $\mathbf{O C 1 0}$ or a urea in OC11, as well as the use of the so-called Takemoto catalyst OC9 having a different chiral backbone, gave the product 3a in only moderate yields and enantioselectivities. Finally, catalyst $\mathbf{O C 1 2}$ having a missing $\mathrm{N}-\mathrm{H}$ bond promoted the reaction at a very slow rate $(<10 \%$ conversion after 4 days $)$. Notably, the diastereoselectivity of the reaction is not much affected by the nature of the catalyst, the product $\mathbf{3} \mathbf{a}$ being systematically obtained as an about 5:1 mixture of the trans and cis diastereomers, respectively.

With optimized reaction conditions in hand, we examined the scope of this original transformation. The results are summarized in Scheme 3. Initially, a series of cyclobutanones $\mathbf{1}$ bearing different $N$-aryl secondary amide activating groups were examined. All of them reacted smoothly with the orthoamino nitrostyrene $\mathbf{2}$ a to afford the desired benzazocinone products $\mathbf{3} \mathbf{b}-\mathbf{j}$ and ent-3k in fair to good yields along with high to excellent enantioselectivities. The absolute configuration of product $\mathbf{3 b}$ was unambiguously determined to be $(5 S, 6 R)$ by X-ray diffraction techniques (see the Supporting Information) ${ }^{[13]}$ which is consistent with previous results. ${ }^{[10]} \mathrm{In}$ line with previous studies on organocatalytic Michael additions with secondary $\beta$-ketoamides, ${ }^{[10,14]}$ substrates bearing a $\mathrm{R}^{1}$ electron-withdrawing substituent systematically afforded better enantioselectivities, which was attributed to the higher acidity of the secondary amide $\mathrm{N}-\mathrm{H}$ proton in these cases resulting in more compact and better-defined transition states in the Michael addition step. As a scope limiting issue, the analog of $\mathbf{1}$ having a $N$-tert-butyl group in place of the $N$-aryl substituent did not react with nitrostyrene $\mathbf{2}$ a using catalyst OC1, while catalyst OC9 promoted only the corresponding Michael addition at a slow rate without evidence for any fragmentation. ${ }^{[10,15]}$ The secondary amide $N$-aryl substituent in 1 seems essential for the overall cascade to proceed, probably a consequence of the higher acidity, and thus higher electron-withdrawing character, of secondary $N$-aryl amides compared to $N$-alkyl amides.${ }^{[14 a]}$ Modifications of the orthoamino nitrostyrene substrate were also possible as illustrated by the introduction of an alkyl or a halogen substituent on the phenyl ring in $\mathbf{3 1}$ and $\mathbf{3} \mathbf{m}$, respectively, and by variations of the carbamate protecting group in $\mathbf{3 n}-\mathbf{p}$, while maintaining high levels of enantioselectivity. If all reactions proceeded with high to excellent enantioselectivities, their diastereoselectivities were found to be influenced by steric factors. For 

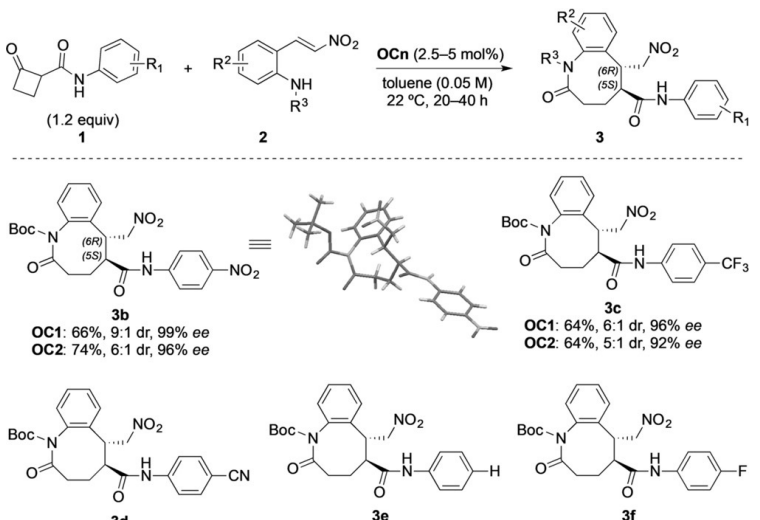

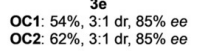

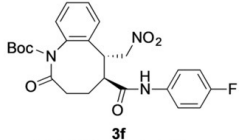

oc2: $72 \%, 6: 1$ dr, $95 \%$ ee

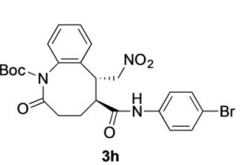

$3 \mathrm{~h}$
OC1: $65 \%, 5: 1 \mathrm{dr}, 88 \%$ ee
OC2: $66 \%, 5: 1 \mathrm{dr}, 88 \%$ ee
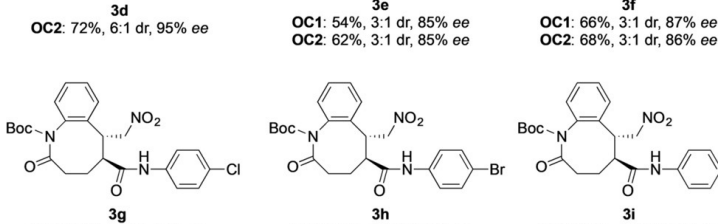

OC1: $67 \%, 5: 1 \mathrm{dr}, 86 \%$ ee
OC2: $66 \%, 5: 1 \mathrm{dr}, 88 \%$ ee

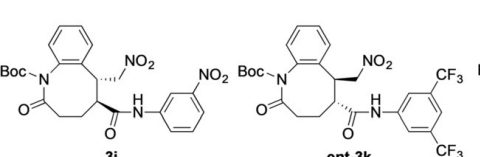

OC1: $64 \%, 15: 1 \mathrm{dr}, 94 \%$ ee

oc7: $85 \%, 10: 1 \mathrm{dr}, 97 \%$ ee

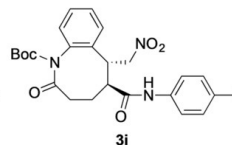

OC2: $64 \%, 5: 1$ dr, $90 \%$ ee
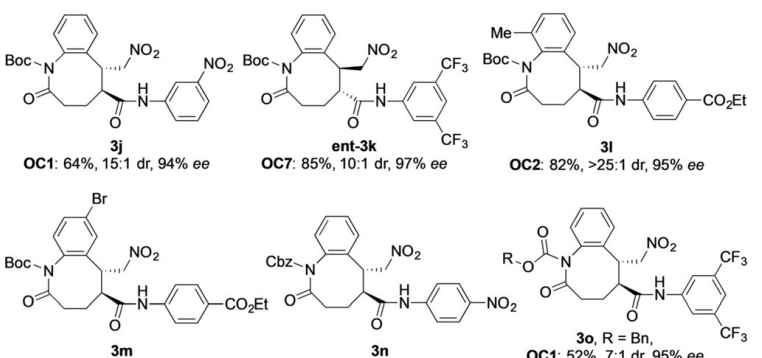

(2) $82 \%, 251,1$ dr $95 \%$ oc2: $50 \%, 8: 1 \mathrm{dr}, 99 \%$ ee

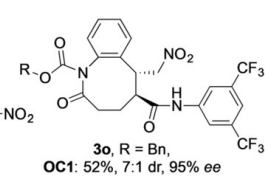

3, $R=E t_{\text {, }}$,

Scheme 3. Substrates scope. Reactions were performed on a $0.1-$ $1.0 \mathrm{mmol}$ scale. Yields for isolated pure products. The $\mathrm{dr}$ values were determined by ${ }^{1} \mathrm{H}$ NMR analysis of the crude reaction mixtures, and $e e$ were determined for the pure products by HPLC analyses on chiral stationary phases.

example, products $\mathbf{3} \mathbf{b}$ and $\mathbf{3} \mathbf{j}$ only differ by the position of the para- or meta- $\mathrm{NO}_{2}$ substituent on the secondary amide phenyl ring and were obtained as 9:1 and 15:1 mixtures of diastereomers, respectively. Also, $\mathbf{3 1}$ is an ortho-methylated analog of $\mathbf{3} \mathbf{a}$ on the fused benzo ring, which strongly influenced the diastereoselectivity (5:1 dr for 3a vs. $>25: 1 \mathrm{dr}$ for 31). DFT calculations indicated a stabilization energy of about $10 \mathrm{~kJ} \mathrm{~mol}^{-1}$ for the trans diastereomers of $\mathbf{3} \mathbf{a}$ and $\mathbf{3 1}$ relative to their cis isomers (see the Supporting Information). Some degree of thermodynamic control of the diastereoselectivity could be evidenced: $3 \mathbf{k}$ (the enantiomer of ent-3k) was prepared using catalyst OC1 (70\% yield, 10:1 dr, $83 \% e e$ ) and chromatographic techniques allowed us to obtain a sample of $3 \mathbf{k}$ enriched in the minor diastereomer with $\mathrm{dr}=2: 1$. This material was placed back under the reaction conditions with $5 \mathrm{~mol} \% \mathbf{O C 1}$ in toluene. Periodical monitoring of the mixture by ${ }^{1} \mathrm{H}$ NMR analysis of aliquots showed a slow conversion of the minor diastereomer into the major one with $\mathrm{dr}=3.6: 1$ after $20 \mathrm{~h}$ and $\mathrm{dr}=7: 1$ after $50 \mathrm{~h}$ without significant decomposition.

To further demonstrate the potential of this enantioselective synthesis of benzazocinones, we examined their basecatalyzed ring contraction into the corresponding glutarimides exploiting the reactivity of the pendant $\mathrm{N}$-aryl secondary amide group (Scheme 4). Notably, chiral glutarimide moieties are found in biologically active natural and synthetic
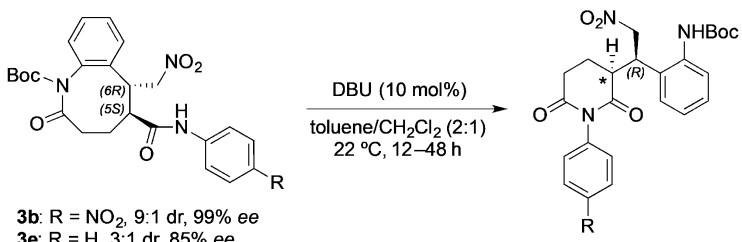

3b: $\mathrm{R}=\mathrm{NO}_{2}, 9: 1 \mathrm{dr}, 99 \%$ ee

3e: $R=H, 3: 1 \mathrm{dr}, 85 \%$ ee

3h: $R=B r, 5: 1 \mathrm{dr}, 88 \%$ ee

3i: $\mathrm{R}=\mathrm{I}, 5: 1 \mathrm{dr}, 90 \%$ ee

4b: $96 \%, 6: 1 \mathrm{dr}, 97 \%$ and $95 \%$ ee 4e: $65 \%, 2: 1 \mathrm{dr}, 83 \%$ and $84 \%$ ee 4h: $70 \%, 3: 1 \mathrm{dr}, 85 \%$ and $85 \%$ ee 4i: $70 \%, 2: 1 \mathrm{dr}, 85 \%$ and $85 \%$ ee

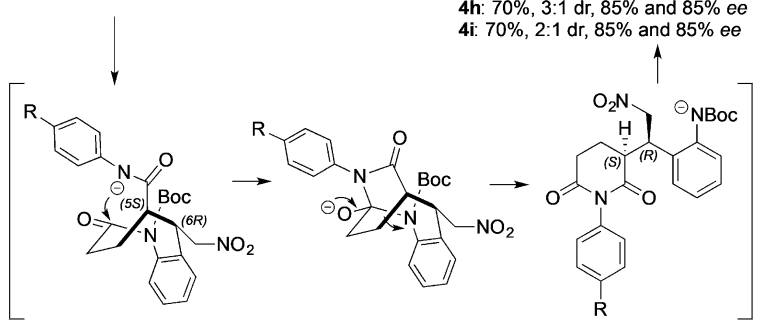

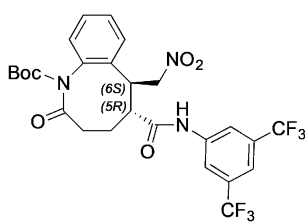

ent-3k: $10: 1 \mathrm{dr}, 97 \%$ ee

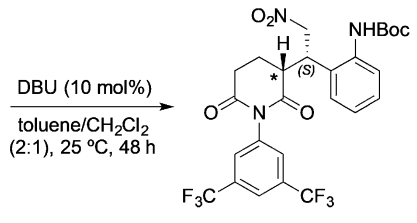

ent-4k: $71 \%, 3: 1 \mathrm{dr}, 96 \%$ and $97 \%$ ee
Scheme 4. Ring contraction of benzazocinones into glutarimides. The major diastereomers are depicted, dr values were determined by ${ }^{1} \mathrm{H}$ NMR analysis of the crude reaction mixtures, $e e$ are reported for the major and minor diastereomers, respectively, and were determined for the pure products by HPLC analyses on chiral stationary phases. $\mathrm{DBU}=$ 1,8-Diazabicyclo[5.4.0]undec-7-ene.

products including marketed drugs, ${ }^{[16]}$ but enantioselective methods for their synthesis remain scarce. ${ }^{[7,17]}$ A screening of archetypal Brønsted and Lewis bases with substrate $\mathbf{3 b}$ (Table S1 in the Supporting Information) allowed identifying DBU as a competent catalyst for the desired transformation, which after optimization afforded the glutarimide $\mathbf{4 b}$ in good yield without significant erosion of optical purity but some epimerization at the imide enolizable position. Similarly, the benzazocinones $\mathbf{3 e}, \mathbf{3} \mathbf{e h}, \mathbf{3}$ ei and ent-3 k reacted with DBU to afford the corresponding glutarimides $4 \mathbf{e}, \mathbf{4 h}, \mathbf{4 i}$, and ent-4k. Mechanistically, this transformation may proceed by a thermodynamically-controlled transannular ring-rearrangement involving the Brønsted base properties of the catalyst. A pure sample of the minor diastereomer epi-ent-4 $\mathbf{k}$ was obtained by semi-preparative HPLC techniques and submitted back to the reaction conditions, which afforded a 3:1 mixture of ent-4k 
and epi-ent-4k. This experiment probed some degree of thermodynamic control in the diastereoselectivity of the ring rearrangement reaction, probably owing to a DBU-catalyzed epimerization at the imide enolizable position. DFT calculations allowed a tentative assignment of the relative configuration in ent-4 $\mathbf{k}$ with a stabilization energy of $7.5 \mathrm{~kJ} \mathrm{~mol}^{-1}$ for the $(R, S)$ diastereomers depicted in Scheme 4 (see the Supporting Information for details). It is remarkable that glutarimides $4 \mathbf{b}, \mathbf{4} e, \mathbf{4 h}, \mathbf{4 i}$, and ent-4k overall derive from the corresponding activated cyclobutanones $\mathbf{1}$ by an enantioselective ring expansion- ring contraction approach. ${ }^{[18]}$

In summary, an enantioselective synthesis of benzazocinones has been elaborated based on a Michael addition- fouratom ring expansion cascade from activated cyclobutanones and ortho-amino nitrostyrenes using bifunctional aminocatalysts. This newly developed approach allows a straightforward access to a class of molecules usually difficult to synthesize in optically active form, from readily available starting materials, and under mild conditions. The benzazocinone products can be further converted into functionalized glutarimide derivatives without loss of the enantiomeric purity by a basecatalyzed ring contraction.

Supporting information for this article is given via a link at the end of the document. It contains detailed experimental procedures, full characterization data, details of the computational studies and single crystal X-ray diffraction analysis data for $\mathbf{3 b}$.

\section{Acknowledgements}

Financial support from the Agence Nationale de la Recherche (ANR-13-JS07-0002-01), Aix-Marseille Université, Centrale Marseille, and the Centre National de la Recherche Scientifique (CNRS) is gratefully acknowledged. Y.Z. thanks the National Natural Science Foundation of China (no. 21602089) for support. Y.-L.W. thanks the China Scholarship Council (no. 201508330296) for support. We thank Dr. Michel Giorgi (Aix-Marseille Université) for the X-ray structural analysis, and Dr. Nicolas Vanthuyne and Ms. Marion Jean (Aix-Marseille Université) for HPLC methods.

\section{Conflict of interest}

The authors declare no conflict of interest.

Keywords: nitrogen heterocycles - organocatalysis ring contraction · ring expansion · synthetic methods

[1] For selected recent reviews on medium sized rings, see: a) I. Shiina, Chem. Rev. 2007, 107, 239-273; b) H. M. C. Ferraz, F. I. Bombonato, M. K. Sano, L. S. Longo, Jr., Quím. Nova 2008, 31 , 885-900; c) A. V. Listratova, L. G. Voskressensky, Synthesis 2017, 49, 3801-3834; d) U. Nubbemeyer, Top. Curr. Chem. 2001, 216, 126-196; e) Natural Lactones and Lactams: Synthesis
Occurrence and Biological Activity (Ed.: T. Janecki), WileyVCH, Weinheim, 2013.

2] ל-Clausenamide: a) L. Yang, D.-X. Wang, Q.-Y. Zheng, J. Pan, Z.-T. Huang, M.-X. Wang, Org. Biomol. Chem. 2009, 7, 2628 2634; Balasubramide: b) B. Riemer, O. Hofer, H. Greger, Phytochemistry 1997, 45, 337-341; Sulpinine C: c) J. A Laakso, J. B. Gloer, D. T. Wicklow, P. F. Dowd, J. Org. Chem. 1992, 57, 2066-2071; Asporyzin A: d) M.-F. Qiao, N.-Y. Ji, X.-H Liu, K. Li, Q.-M. Zhu, Q.-Z. Xue, Bioorg. Med. Chem. Lett. 2010, 20, 5677-5680; Benzazocine core of FR900482: e) B. M. Trost, M. K. Ameriks, Org. Lett. 2004, 6, $1745-1748$.

[3] For selected examples of the diastereoselective synthesis of azocanes, see: a) A. Klapars, S. Parris, K. W. Anderson, S. L. Buchwald, J. Am. Chem. Soc. 2004, 126, 3529-3533; b) X. Fang, K. Liu, C. Li, J. Am. Chem. Soc. 2010, 132, 2274-2283; c) P. Kumar, K. Zhang, J. Louie, Angew. Chem. Int. Ed. 2012, 51, 8602-8606; Angew. Chem. 2012, 124, 8730-8734; d) A. Thakur, M. E. Facer, J. Louie, Angew. Chem. Int. Ed. 2013, 52, $12161-$ 12165; Angew. Chem. 2013, 125, 12383-12387; e) C. Zhao, X. Xie, S. Duan, H. Li, R. Fang, X. She, Angew. Chem. Int. Ed. 2014, 53, 10789-10793; Angew. Chem. 2014, 126, 10965-10969; f) S. Wu, R. Zeng, C. Fu, Y. Yu, X. Zhang, S. Ma, Chem. Sci. 2015, 6 $2275-2285 ;$ g) M. H. Shaw, R. A. Croft, W. G. Whittingham, J. F. Bower, J. Am. Chem. Soc. 2015, 137, 8054-8057; h) W. Zhao, H. Qian, Z. Li, J. Sun, Angew. Chem. Int. Ed. 2015, 54, $10005-$ 10008; Angew. Chem. 2015, 127, 10143 -10146; i) B. Zhou, L. Li, X.-Q. Zhu, J.-Z. Yan, Y.-L. Guo, L.-W. Ye, Angew. Chem. Int. Ed. 2017, 56, 4015-4019; Angew. Chem. 2017, 129, 4073-4077.

[4] R. T. Yu, R. K. Friedman, T. Rovis, J. Am. Chem. Soc. 2009, 131, $13250-13251$.

[5] H. A. Khan, K. G. M. Kou, V. M. Dong, Chem. Sci. 2011, 2, 407410.

[6] H. Ni, X. Tang, W. Zheng, W. Yao, N. Ullah, Y. Lu, Angew. Chem. Int. Ed. 2017, 56, 14222-14226; Angew. Chem. 2017, 129 , $14410-14414$.

[7] G. Kang, M. Yamagami, S. Vellalath, D. Romo, Angew. Chem. Int. Ed. 2018, 57, 6527-6531; Angew. Chem. 2018, 130, 66376641.

[8] For selected recent reviews and books on organocatalytic enantioselective cascade reactions, see: a) A. Moyano, R. Rios, Chem. Rev. 2011, 111, 4703-4832; b) C. M. Marson, Chem. Soc. Rev. 2012, 41, 7712-7722; c) C. M. R. Volla, I. Atodiresei, M. Rueping, Chem. Rev. 2014, 114, 2390-2431; d) Y. Wang, H. Lu, P.-F. Xu, Acc. Chem. Res. 2015, 48, 1832-1844; e) F. Vetica, P. Chauhan, S. Dochain, D. Enders, Chem. Soc. Rev. 2017, 46, 1661-1674; f) Catalytic Cascade Reactions (Eds.: P. Xu, W. Wang), Wiley, Hoboken, 2013; g) Stereoselective multiple bondforming transformations in organic synthesis (Eds.: D. Bonne, J. Rodriguez), Wiley, Hoboken, 2015.

[9] For selected recent reviews on ring expansion synthetic strategies, see: a) E. Leemans, M. D'hooghe, N. De Kimpe, Chem. Rev. 2011, 111, 3268-3333; b) J. Christoffers, Catal. Today 2011, 159, 96-99; c) G. Fumagalli, S. Stanton, J. F. Bower, Chem. Rev. 2017, 117, 9404-9432; d) J. R. Donald, W. P. Unsworth, Chem. Eur. J. 2017, 23, 8780-8799; For selected recent examples on ring expansion strategies, see: e) F. Behler, F. Habecker, W. Saak, T. Klüner, J. Christoffers, Eur. J. Org. Chem. 2011, 4231 4240; f) M. Penning, E. Aeissen, J. Christoffers, Synthesis 2015 , 47, 1007-1015; g) C. Kitsiou, J. J. Hindes, P. I'Anson, P. Jackson, T. C. Wilson, E. K. Daly, H. R. Felstead, P. Hearnshaw, W. P. Unsworth, Angew. Chem. Int. Ed. 2015, 54, 15794-15798; Angew. Chem. 2015, 127, 16020-16024; h) M. Roudier, T. Constantieux, A. Quintard, J. Rodriguez, Eur. J. Org. Chem. 2015, 5709-5711; i) J. E. Hall, J. V. Matlock, J. W. Ward, K. V. Gray, J. Clayden, Angew. Chem. Int. Ed. 2016, 55, 11153-11157; Angew. Chem. 2016, 128, 11319-11323; j) R. Costil, Q. Lefebvre, J. Clayden, Angew. Chem. Int. Ed. 2017, 56, 14602-14606; 
Angew. Chem. 2017, 129, 14794-14798; k) T. C. Stephens, M. Lodi, A. M. Steer, Y. Lin, M. T. Gill, W. P. Unsworth, Chem. Eur. J. 2017, 23, 13314-13318; 1) R. Mendoza-Sanchez, V. B. Corless, Q. N. N. Nguyen, M. Bergeron-Brlek, J. Frost, S. Adachi, D. J. Tantillo, A. K. Yudin, Chem. Eur. J. 2017, 23, 13319-13322 m) T. C. Stephens, A. Lawer, T. French, W. P. Unsworth, Chem Eur. J. 2018, 24, 13947-13953; n) N. Wang, Q.-S. Gu, Z.-L. Li, Z. Li, Y.-L. Guo, Z. Guo, X.-Y. Liu, Angew. Chem. Int. Ed. 2018, 57, 14225-14229; Angew. Chem. 2018, 130, 14421-14425.

[10] D. Mailhol, M. d. M. Sanchez Duque, W. Raimondi, D. Bonne, T. Constantieux, Y. Coquerel, J. Rodriguez, Adv. Synth. Catal. 2012, 354, 3523-3532.

[11] J. P. Malerich, K. Hagihara, V. H. Rawal, J. Am. Chem. Soc 2008, 130, 14416-14417.

[12] Selected article and recent reviews on bifunctional hydrogenbonding aminocatalysts: a) Z. Zhang, P. R. Schreiner, Chem. Soc. Rev. 2009, 38, 1187-1198; b) P. Chauhan, S. Mahajan, U. Kaya, D. Hack, D. Enders, Adv. Synth. Catal. 2015, 357, 253 281; c) X. Fang, C.-J. Wang, Chem. Commun. 2015, 51, 1185 1197; d) B.-L. Zhao, J.-H. Li, D.-M. Du, Chem. Rec. 2017, 17, $994-1018$.

[13] CCDC 1831606 (3b) contains the supplementary crystallographic data for this paper. These data can be obtained free of charge from The Cambridge Crystallographic Data Centre

[14] a) M. d. M. Sanchez Duque, O. Baslé, N. Isambert, A. GaudelSiri, Y. Génisson, J.-C. Plaquevent, J. Rodriguez, T. Constantieux, Org. Lett. 2011, 13, 3296-3299; b) A. Quintard, D. Cheshmedzhieva, M. d. M. Sanchez Duque, A. Gaudel-Siri, J.V. Naubron, Y. Génisson, J.-C. Plaquevent, X. Bugaut, J. Rodriguez, T. Constantieux, Chem. Eur. J. 2015, 21, 778-790.

[15] For other organocatalytic Michael additions of cyclobutanones to nitroolefins, see: a) F. Capitta, A. Frongia, J. Ollivier, D. J.
Aitken, F. Secci, P. P. Piras, R. Guillot, Synlett 2015, 26, 123-126; b) A. Luridiana, A. Frongia, D. J. Aitken, R. Guillot, G. Saraisc, F. Secci, Org. Biomol. Chem. 2016, 14, 3394-3403.

[16] a) H. Kiyota, Top Heterocycl. Chem. 2006, 6, 181-214; b) S. D. Koulocheri, E. N. Pitsinos, S. A. Haroutounian, Curr. Org. Chem. 2008, 12, 1454-1467; c) T. Kataoka, Eur. J. Pharm. 2012, 676, 1-5; d) J. B. Popović-Djordjević, A. S. Klaus, Ž. S. Žižak, I. Z. Matić, B. J. Drakulić, J. Enzyme. Inhib. Med. Chem. 2016, 31,915-923; e) J. D. Hansen, K. Condroski, M. Correa, G. Muller, H.-W. Man, A. Ruchelman, W. Zhang, F. Vocanson, T. Crea, W. Liu, G. Lu, F. Baculi, L. LeBrun, A. Mahmoudi, G. Carmel, M. Hickman, C.-C. Lu, J. Med. Chem. 2018, 61, $492-$ 503.

[17] a) N. B. Bennett, D. C. Duquette, J. Kim, W.-B. Liu, A. N Marziale, D. C. Behenna, S. C. Virgil, B. M. Stoltz, Chem. Eur. J. 2013, 19, 4414-4418; b) S. Goudedranche, X. Bugaut, T. Constantieux, D. Bonne, J. Rodriguez, Chem. Eur. J. 2014, 20 $410-415$; c) K. Zhang, M. Meazza, V. Dočekal, M. E. Light, J. Veselý, R. Rios, Eur. J. Org. Chem. 2017, 1749-1756; d) S. Mondal, A. Ghosh, S. Mukherjee, A. T. Biju, Org. Lett. 2018, 20 , 4499-4503.

[18] For a related ring expansion - contraction strategy in the racemic series, see: J. E. Hill, J. V. Matlock, Q. Lefebvre, K. G. Cooper, J. Clayden, Angew. Chem. Int. Ed. 2018, 57, 5788-5791; Angew. Chem. 2018, 130, 5890-5893. 